\title{
Determination of Phenol and Chlorophenols at Single-Wall Carbon Nanotubes/Poly(3,4-ethylenedioxythiophene) Modified Glassy Carbon Electrode Using Flow Injection Amperometry
}

\author{
Negussie Negash, ${ }^{1}$ Hailemichael Alemu, ${ }^{2}$ and Merid Tessema ${ }^{1}$ \\ ${ }^{1}$ Department of Chemistry, Addis Ababa University, P.O. Box 1176, Addis Ababa, Ethiopia \\ ${ }^{2}$ Department of Chemistry and Chemical Technology, National University of Lesotho, P.O. Box 180, Mailroom 127, Roma, Lesotho
}

Correspondence should be addressed to Hailemichael Alemu; hm.alemu@nul.ls

Received 28 February 2014; Accepted 19 March 2014; Published 16 April 2014

Academic Editors: P. Campíns-Falcó, F. Kandemirli, and J. J. Santana-Rodríguez

Copyright (C) 2014 Negussie Negash et al. This is an open access article distributed under the Creative Commons Attribution License, which permits unrestricted use, distribution, and reproduction in any medium, provided the original work is properly cited.

\begin{abstract}
Phenol and chlorophenols were investigated using single-wall carbon nanotubes (SWCNT) and poly(3,4-ethylenedioxythiophene) (PEDOT) composite modified glassy carbon electrode (SWCNT/PEDOT/GCE) as a detector in flow injection system. Optimization of experimental variables such as the detection potential, flow rate, and $\mathrm{pH}$ of the carrier solution (0.1 $\mathrm{M}$ sodium acetate) for the determination of phenol (P), 4-chlorophenol (CP), 2,4-dichlorophenol (DCP), 2,4,6-trichlorophenol (TCP), and pentachlorophenol (PCP) were performed. Under these conditions, analytical parameters were calculated from the calibration curve of measured amperometric responses as a function of concentrations of phenol and chlorophenols. The designed electrode exhibited very good analytical performance. The designed electrode was tested with 20 repetitive injections of each analyte and showed good operational stability. The analytical performance of the SWCNT/PEDOT/GCE electrode under flow through conditions was tested and was found to be impressive. The electrode showed a wider dynamic range for the detection of phenol and chlorophenols with low limits of detection compared with other enzymatic and nonenzymatic sensors. These results suggest that the method is quite useful for the analysis and monitoring of phenols and chlorophenols.
\end{abstract}

\section{Introduction}

Phenolic compounds include a large class of compounds that are common in nature and partly formed as a result of biodegradation of natural compounds. They are widely distributed in fruits and vegetables with a wide range of phenolic contents and species [1]. Phenolic compounds are also formed in a number of industrial processes and released to wastewater streams from these industries. Many phenols especially chlorophenols are used in the manufacture of chemicals that are used as preservatives for woods, textile, and leathers [2]. Phenol derivatives are known to be highly toxic to man and to aquatic organisms. They possess carcinogenic and immunosuppressive properties [3] and are highly resistant to biological degradation and persistent in the environment [2]. As a result the United States Environmental Protection Agency (EPA) and the European Union (EU) have included these phenolic compounds in their list of primary pollutants
[4]. In fact the benefits related to consumption of phenolicrich foods are associated with their antioxidant activities which are determined by their reactivity as hydrogen or electron donating agent $[5,6]$.

The applications of phenol and its derivatives represent potential source of pollution and affect aquatic organisms [7] including algae and aquatic spermatophytes. These toxic phenols and phenolic derivatives are released to the environment and their identification and quantification are of great importance in environmental monitoring.

Various analytical methods, such as liquid chromatography (LC), gas chromatography (GC), capillary electrophoresis, and fluorometry, have been reported for the determination of phenols and phenol derivatives $[3,5,8-10]$. These methods are sensitive, specific, and precise, but most of them are expensive and time consuming and require skilled technicians and some require derivatization procedures. 
Electrochemical methods are the method of choice for the sensitive, rapid, and precise determination of phenol and its derivatives. Electrochemical oxidation of phenols and chlorophenols [11] and the use of electrochemical sensors as detectors in flow injection analysis [12] produced enhanced selectivity, sensitivity, and reproducibility of determinations. Amperometric methods mainly use electrochemical sensors and biosensors as detectors in FIA. Tyrosinase (Tyr) based sensors have been the most widely used amperometric biosensor for determination of phenols and were prepared in a number of matrices and conventional electrodes, including carbon paste [13], conducting polymers [14, 15], CNT conducting polymer composites [16, 17], self-assembled monolayer [18], and silica sol-gel composite [19]. Laccase based biosensors [20, 21] and horseradish peroxidase (HRP) [22] based electrochemical detectors coupled with flow injection system for the determination of phenol and phenol derivatives were also reported. In the investigated biosensors, the enzymes were either individually immobilized or composite multienzyme systems were immobilized on conventional electrodes to determine the phenolic compounds.

The use of enzyme modified electrodes significantly decreases surface fouling of electrodes. However, the high cost, the problem of immobilization process, low stability, and short operating time limit their practical application. Thus, modification of bare electrodes with nonbiological materials, such as conducting polymers, is an alternative to prevent electrode surface fouling [11, 23]. Poly(3,4ethylenedioxythiophene), PEDOT, which is a relatively new and well-known conjugated polymer, has received relatively high attention because of its high electrical conductivity and excellent environmental stability. Thus, PEDOT has emerged as one of the most stable and promising electrode materials offering the possibility modification with different chemical groups for the determination of phenols, dopamine and ascorbic acid [24], paracetamol [25], N-acetylp-aminophenol and p-aminophenol [26], and niclosamide [27].

Carbon nanotubes have remarkable electrical properties, such as high specific surface area and chemical stability [2830 ], and can be used as electrode material to promote electron transfer between electroactive species and the electrode. Addition of CNT to conducting polymer, such as PEDOT, results in a significant increase in the mechanical properties and enhances electrical properties of the polymer by facilitating the charge transfer processes. Thus, in recent years, more and more attentions were inclined to the synthesis of conducting polymer/CNT composites that have special properties of the individual components in a synergistic manner $[31,32]$.

Although a number of electrode materials based on CNTconducting polymer composite were used for the determination of phenol and its derivatives in batch system, few researchers investigated the use of CNT-conducting polymer composites as detectors in flow injection analysis. Glassy carbon electrode modified with multiwall carbon nanotubes dispersed in polyethylenimine composite was used as amperometric working electrode for flow injection determination of phenolic compounds [33].
The preparation of new composite materials that have distinct properties which were not observed in the individual components was the objective of this work. The study led to the development of SWCNT/PEDOT modified glassy carbon electrode (SWCNT/PEDOT/GCE) for the determination of phenol and chlorophenols. The modified electrode was used as an amperometric detector in flow injection system with improved qualities such as simplicity of electrode preparation, wider linear range, low detection limit, and good stability. To the best of our knowledge the modification and application of the SWCNT/PEDOT/GCE modified electrode as an amperometric phenol and chlorophenols detector had not been reported so far.

\section{Experimental}

2.1. Chemicals. SWCNT (mixture of metallic and semiconducting), 3,4-ethylenedioxythiophene (EDOT) monomer, and pentachlorophenol were from Adrich, 4-chlorophenol, 2,4-dichlorophenol, 2,4,6-trichlorophenol, and phenol were from Fluka (Buchs, Switzerland), acetic acid and DMF were from Merck, tetrabutylammonium perchlorate and acetonitrile were from Sigma-Aldrich, and other chemicals were from the Republic of South Africa. Helium gas (Air Products, RSA) was employed for the deaeration of the carrier solution of the flow system. All chemicals were of analytical grade and were used without further purifications. All solutions were prepared using ultrapure water of resistivity $18.2 \mathrm{M} \Omega$ $\mathrm{cm}$ obtained from ELGA PURELAB Option-Q (UK) water purification system.

2.2. Instrumentation. Amperometric and Voltammetric measurements were performed using Epsilon Electrochemical Analyzer attached to BAS C2 cell stand (both from BASi instrumentation, USA). EDOT polymerization was carried out with BAS 100B electrochemical work station (BAS, USA). A conventional three-electrode cell was used for measurements, with a bare glassy carbon electrode (GCE) (3 mm diameter), SWCNT/PEDOT/GCE was used as the working electrode, $\mathrm{Ag} / \mathrm{AgCl}(3 \mathrm{M} \mathrm{NaCl})$ was used as a reference electrode, and a platinum wire was used as counter electrode. The flow system consisted of a BAS pump (Model PM-92E; USA), a sample injection valve, and a thin-layer electrochemical detector (BASi LC-4C, USA), with a flowthrough cell. The electrochemical detector was connected to the Epsilon Electrochemical Analyzer. Two GCE modified with SWCNT/PEDOT (in series configuration) were used as working electrodes, while $\mathrm{Ag} / \mathrm{AgCl}$ electrode $(3 \mathrm{M} \mathrm{NaCl})$ (RE-1; BASi) served as the reference electrode. The counter electrode was the bulk plate of the cell, made of stainless steel. The thickness of the layer in the cell was $0.0127 \mathrm{~cm}$. The $\mathrm{pH}$ of the solutions was measured using HANNA HI 8314 pH-meter, while for electrode cleaning iS Integral Systems ultrasonic bath was used.

2.3. Preparation of Modified Electrode. Prior to surface modification, the bare glassy carbon electrode was polished with a 0.3 and $0.05 \mu \mathrm{m}$ alumina slurry and washed with tap 


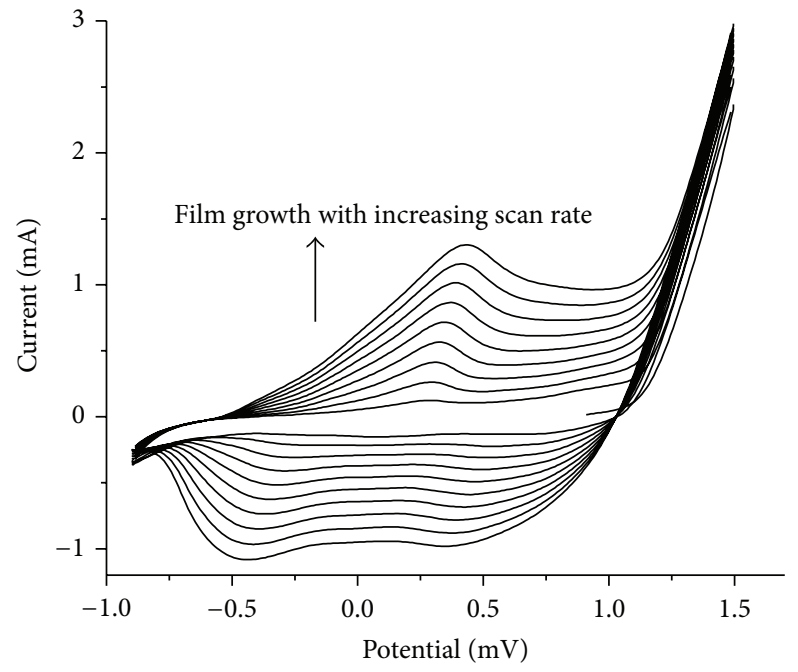

FIGURE 1: Repeated cyclic voltammograms of PEDOT film growth at a glassy carbon electrode in a solution of $0.1 \mathrm{M}$ tetrabutylammonium perchlorate in acetonitrile containing $0.01 \mathrm{M}$ EDOT, $10 \mathrm{~V} \mathrm{~s}^{-1}$ scan rate, and potential range $-0.9-1.5 \mathrm{~V}$.

water several times and sonicated in ultrapure water bath for two minutes. Before electropolymerization, the polished electrode was pretreated using cyclic voltammetry cycling for 10 minutes between -0.9 and $+1.5 \mathrm{~V}$ at $10 \mathrm{~V} \mathrm{~s}^{-1}$ containing $0.1 \mathrm{M}$ tetrabutylammonium perchlorate in acetonitrile. Then the PEDOT was electrodeposited on the electrode in the above solution containing $10 \mathrm{mM}$ EDOT by cycling the potential between -0.9 and $+1.5 \mathrm{~V}$. The PEDOT film was allowed to grow on the GC surface for ten successive scans as can be seen from the increasing anodic and cathodic peak current densities. The polymer film was washed with ultrapure water to remove the supporting electrolyte and unreacted monomer and dried. A PEDOT/SWCNT/GCE multilayer film is formed by casting of a $20 \mu \mathrm{L}$ of the dispersed SWCNT in DMF (1 mg SWCNT: $1 \mathrm{~mL}$ DMF) over GCE and dried for an overnight and coated with the PEDOT [34]. In order to determine the optimum amount of polymer coating 5, 10,20,40, and 60 cycles of CV scans of PEDOT polymerization were carried out followed by casting of $20 \mu \mathrm{L}$ of the dispersed SWCNT onto the PEDOT/GCE.

\section{Results and Discussion}

3.1. Electrochemical Behavior of Phenol at Bare and PEDOT Modified Glassy Carbon Electrodes. In the determination of phenol at bare glassy carbon electrodes (figure not shown) the oxidation peak decreased markedly with successive cycles due to the electrodeposition of nonconducting polymeric oxidation product of phenol as cited in the literature $[23,35]$. The response disappeared totally after the third cycle owing to the adsorption of phenol oxidation products followed by electrode fouling. The bare GCE was then modified with PEDOT film. Figure 1 shows the repetitive cyclic voltammograms illustrating the continuous growth of the PEDOT on GCE surface. The thickness of the film was controlled by the

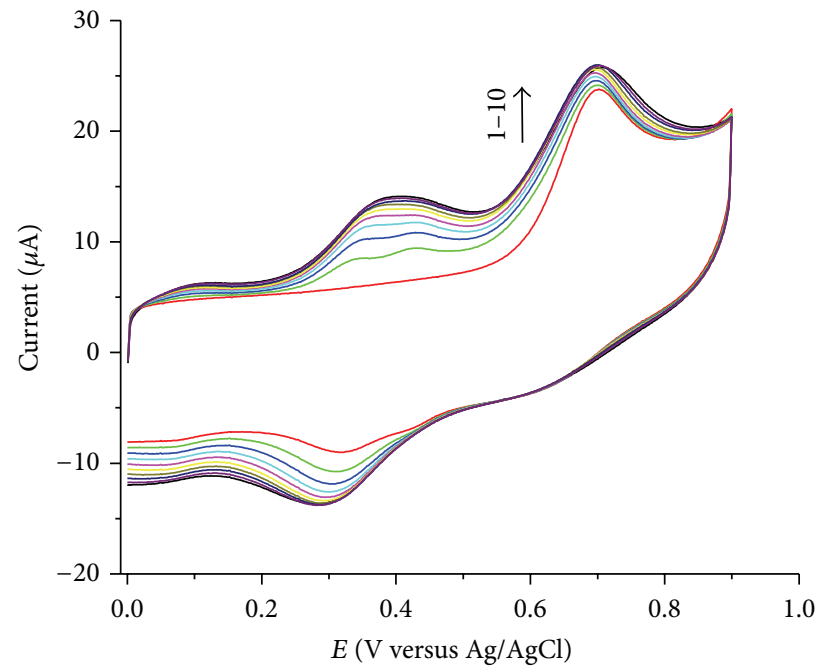

Figure 2: Cyclic voltammogram of $1 \times 10^{-4} \mathrm{M}$ phenol (10 cycles) at PEDOT/GCE modified electrode in $0.1 \mathrm{M}$ acetate buffer $\mathrm{pH} 7$ and scan rate of $50 \mathrm{mV} \mathrm{s}^{-1}$

number of cycles. The continuous increase of the current with the cycle number reveals the formation and expansion of a conducting phase at the electrode surface.

Using cyclic voltammetry the response current for phenol oxidation at PEDOT modified electrode was investigated (see Figure 2). In contrast to the response of the bare GCE to phenol oxidation, the PEDOT modified electrode gave much pronounced current responses. Due to the electrocatalytic effect of the polymer, the shape and the response current are different from those of the bare GCE. The oxidation peak of phenol increased markedly with successive runs at the PEDOT/GCE and the response becomes reproducible after the tenth potential cycle as reported earlier [36]. It can be seen that the use of PEDOT coated GCE sensor also can overcome the problem of passivation.

The GCE then was modified with PEDOT followed by coating with SWCNT. The excellent mechanical and electrical properties of carbon nanotubes help to transport electrons over long distances, and this quality gives the advantage of fabricating many polymer nanocomposites that have good mechanical and/or electrical properties [37]. The responses of $1 \times 10^{-4} \mathrm{M}$ phenol obtained at SWCNT/PEDOT/GCE multilayer film for different numbers of cycles of the film formation are shown in Figure 3.

The lowest number of scans (5 cycles) gave broad voltammograms, while the upper scans (60 cycles) had low sensitivity and long response time due to slow penetration of the analyte molecule into the conducting polymer film. Hence the best combination, having large sensitivity and short response time, was selected to be 10 cycles of PEDOT polymerization over the bare electrode followed by casting of $20 \mu \mathrm{L}$ dispersed SWCNT.

Cyclic voltammograms recorded for the oxidation of $1 \times 10^{-4} \mathrm{M}$ phenol at bare GCE, PEDOT/GCE, SWCNT/GCE, and SWCNT/PEDOT/GCE are shown in Figure 4. The peak current and the corresponding peak potential recorded 


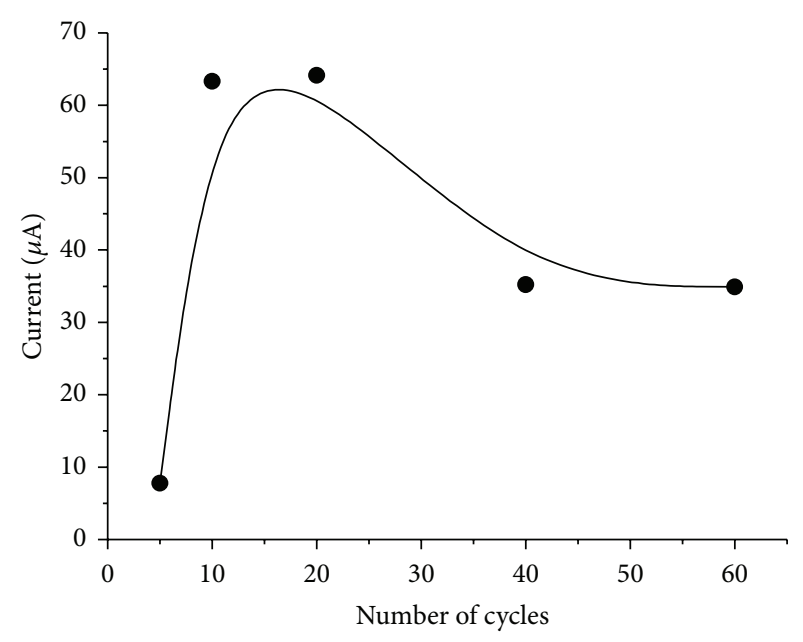

FIGURE 3: The effect of polymer film thickness on the sensor response to $1 \times 10^{-4} \mathrm{M}$ phenol at SWCNT/PEDOT/GCE in $0.1 \mathrm{M}$ acetate buffer, $\mathrm{pH}$ 6; other conditions are shown in Figure 2.

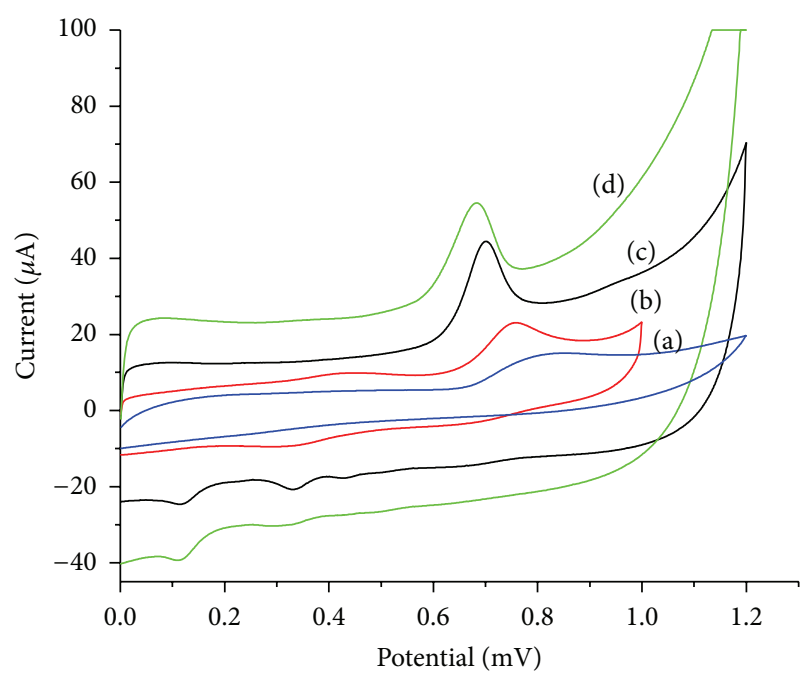

FIGURE 4: Cyclic voltammograms of $1 \times 10^{-4} \mathrm{M}$ phenol at GCE (a), PEDOT/GCE (b), SWCNT/PEDOT/GCE (c), and SWCNT/GCE (d); $0.1 \mathrm{M}$ sodium acetate buffer solution, $\mathrm{pH} 6$; scan rate of $50 \mathrm{mV} \mathrm{s}^{-1}$.

for the bare GCE, PEDOT/GCE, SWCNT/GCE, and SWCNT/PEDOT/GCE are $4.63 \mu \mathrm{A}$ and $0.851 \mathrm{~V}, 13.64 \mu \mathrm{A}$ and $0.758 \mathrm{~V}, 22.60 \mu \mathrm{A}$ and $0.683 \mathrm{~V}$, and $25.05 \mu \mathrm{A}$ and $0.701 \mathrm{~V}$, respectively. This shows that the SWCNT/PEDOT/GCE produced significant increase in the peak current which is the result of incorporation of CNTs into the PEDOT polymer resulting in a synergic effect.

Efficiently dispersed SWCNTs establish a strong affinity with the surrounding polymer matrix and these principles were used to cast SWCNTs on the PEDOT polymer coated GCE. The designed electrode, SWCNT/PEDOT/GCE, has relatively good sensitivity to phenol oxidation and was used as a detector in the flow injection system for the determination of phenol and chlorophenols. Moreover in flow through systems the flowing carrier solution continuously cleans the surface of the electrode and removes reaction products and impurities from the electrode surface [38].

\subsection{Flow Injection Analysis of Phenol and Its Derivatives at SWCNT/PEDOT/GCE}

3.2.1. Experimental Variables for Flow Injection Analysis of Phenol and Chlorophenols. The electrochemical performance of GCE modified with elctropolymerized PEDOT and dispersed SWCNT was investigated for phenol and chlorophenols using $0.1 \mathrm{M}$ sodium acetate carrier solution by flow injection analysis. The influences of the applied potential, flow rate, and effect of the $\mathrm{pH}$ on the amperometric signal of phenol and chlorophenols were studied.

To investigate the effect of modification of the electrode on the working potential, experiments were carried out on the bare GCE and SWCNT/PEDOT/GCE. As shown in Figure 5, similar trends of hydrodynamic responses (sigmoidal shape plots) for $1 \times 10^{-4} \mathrm{M}$ of phenol and chlorophenols were observed. The response for phenol oxidation at bare GCE shows a dramatic decrease of the current response as observed earlier [38] and at SWCNT/PEDOT/GCE the current signal increased in all cases, which can be justified by the facilitated electron transfer offered by SWCNT.

As the flow rate affects the detection limit, sensitivity, and accuracy of the analysis, the effect of the flow rate on phenol and chlorophenols oxidation was investigated. Solutions of $1 \times 10^{-4} \mathrm{M}$ concentrations of each analyte were injected consecutively to the carrier solution ( $0.1 \mathrm{M}$ sodium acetate) at flow rates ranging between 0.1 and $2 \mathrm{~mL} \mathrm{~min}^{-1}$. It was observed that the amperometric current responses increased with an increase in flow rate up to about $1.0 \mathrm{~mL} \mathrm{~min}^{-1}$ for phenol and chlorophenols. As the flow rate increases the dispersion decreases that results in decrease of the residence time and concurrently increases the sensitivity. At relatively higher flow rate (greater than $1.2 \mathrm{~mL} \mathrm{~min}^{-1}$ ) the amperometric current signal decreased, as shown in Figure 6, as previously observed for enzyme based FIA of phenols [38]. Such trends could be explained by the fact that as the sample passes faster through the electrode the smaller would be the fraction of the analyte that would be oxidized followed by a decrease in the amperometric signal. Also the electron transfer and mass transfer rate are not significantly different [18]. The optimum flow rate of the carrier solution for sharp peaks and high sensitivity observed were in the range of 0.9 to $1.2 \mathrm{~mL} \mathrm{~min}^{-1}$.

The $\mathrm{pH}$ of the carrier buffer solution used for the determination of phenol and its derivatives affects the amperometric peak current of the analytes. Figure 7 shows the influence of $\mathrm{pH}$ upon the response of $1 \times 10^{-4} \mathrm{M}$ phenol and chlorophenols at SWCNT/PEDOT/GCE in the $\mathrm{pH}$ range of $3-10$. As can be seen from the figure, the current gradually increased with an increase in $\mathrm{pH}$ from 3 to 7 . However, when the $\mathrm{pH}$ was further increased to 10 the peak current dramatically decreased. Therefore, considering the sensitivity of the determination of phenol and chlorophenols, optimum pH 7 for phenol, 4-chlorophenol, 2,4-dichlorophenol, and 


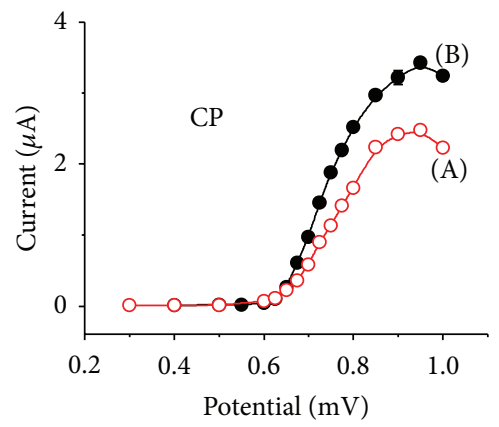

(a)

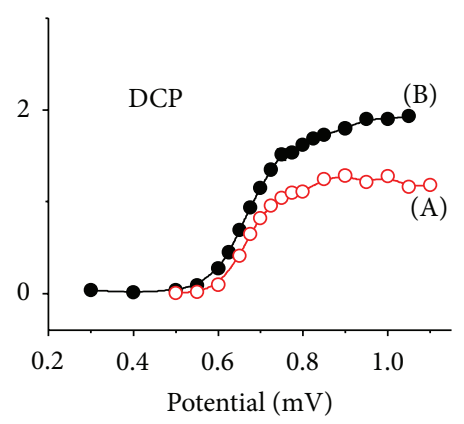

(b)

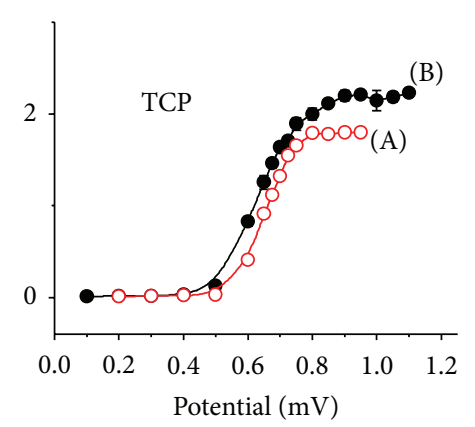

(c)

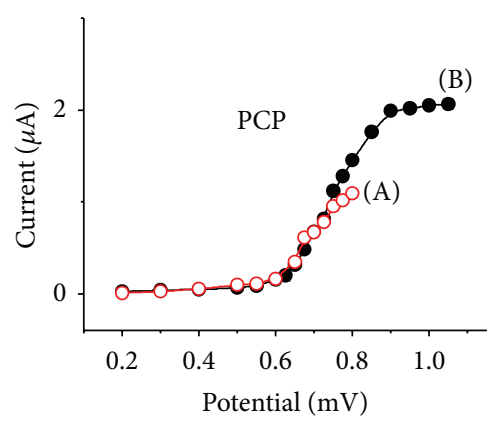

(d)

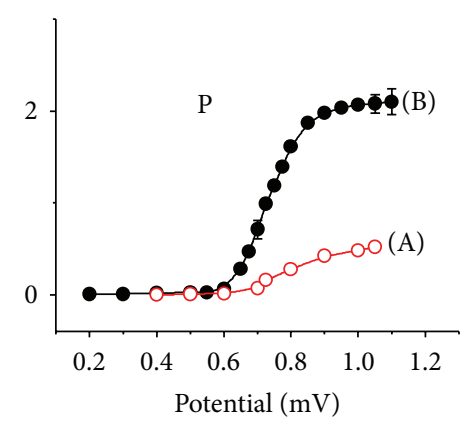

(e)

FIGURE 5: Effect of the applied potential on the flow injection response for $1 \times 10^{-4} \mathrm{M}$ 4-chlorophenol (CP), 2,4-dichlorophenol (DCP), 2,4,6trichlorophenol (TCP), pentachlorophenol (PCP), and phenol (P) at bare GCE (A) and SWCNT/PEDOT/GCE (B); flow rate: 1.0 mL min ${ }^{-1}$; carrier solution: sodium acetate buffer $(0.1 \mathrm{M}) ; \mathrm{pH}, 6$.

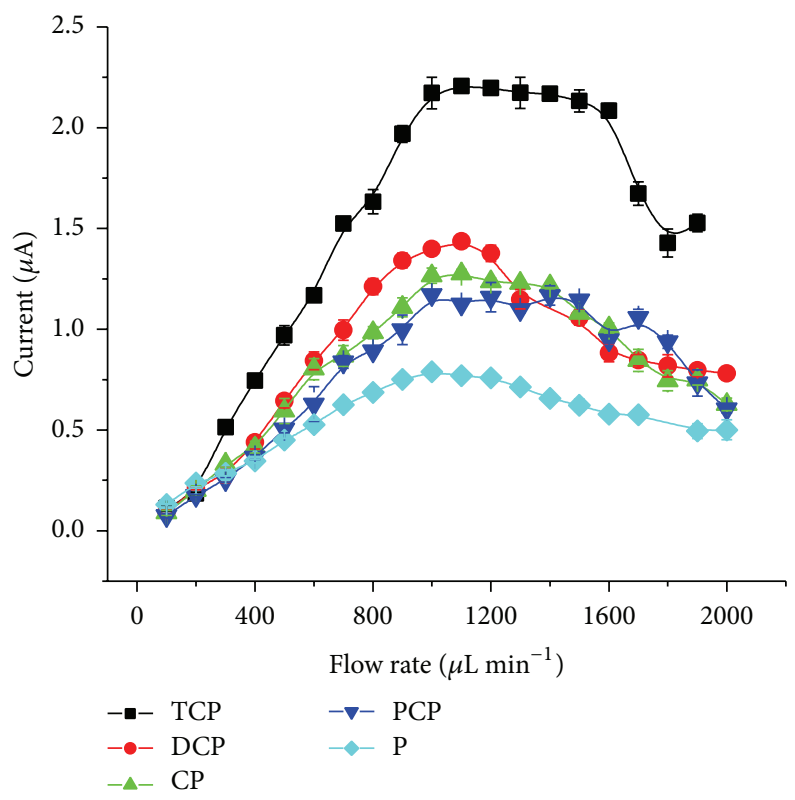

FIGURE 6: The amperometric current response of $1 \times 10^{-4} \mathrm{M}$ phenol (P), pentachlorophenol (PCP), 4-chlorophenol (CP), 2,4-dichlorophenol (DCP), and 2,4,6-trichlorophenol (TCP), at SWCNT/PEDOT/GCE modified electrode at different flow rates. Carrier solution: sodium acetate buffer $(0.1 \mathrm{M})$; $\mathrm{pH}$ 7, applied potential: $0.725 \mathrm{~V}$ for phenol and 4-chlorophenol, $0.7 \mathrm{~V}$ for 2,4-dichlorophenol and 2,4,6-trichlorophenol, and $0.75 \mathrm{~V}$ for pentachlorophenol. 


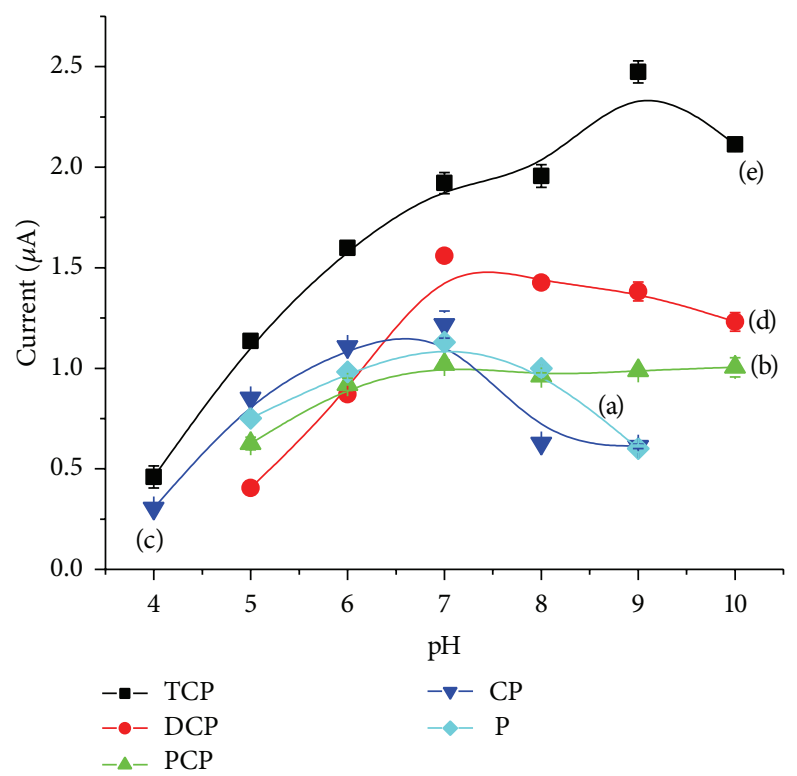

FIGURE 7: Dependence of the current response of $1 \times 10^{-4} \mathrm{M}$ phenol (a), pentachlorophenol (b), 4-chlorophenol (c), 2,4-dichlorophenol (d), and 2,4,6-trichlorophenol (e) at SWCNT/PEDOT/GCE at different $\mathrm{pH}$ of $0.1 \mathrm{M}$ acetate buffer carrier solutions at flow rate of $1.0 \mathrm{~mL} \mathrm{~m}^{-1}$ for phenol and pentachlorophenol, $1.1 \mathrm{~mL} \mathrm{~min}^{-1}$ for 4-chlorophenol, 2,4-dichlorophenol, and 2,4,6-trichlorophenol, applied potential as in Figure 6.

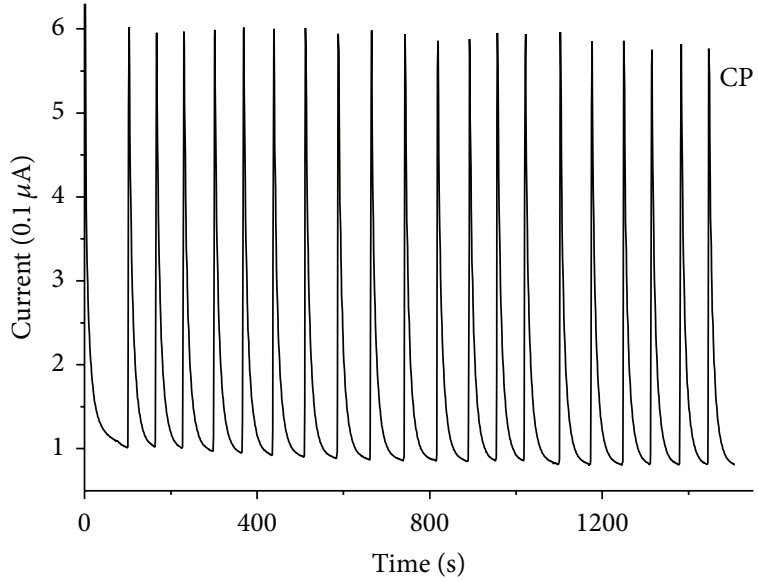

(a)

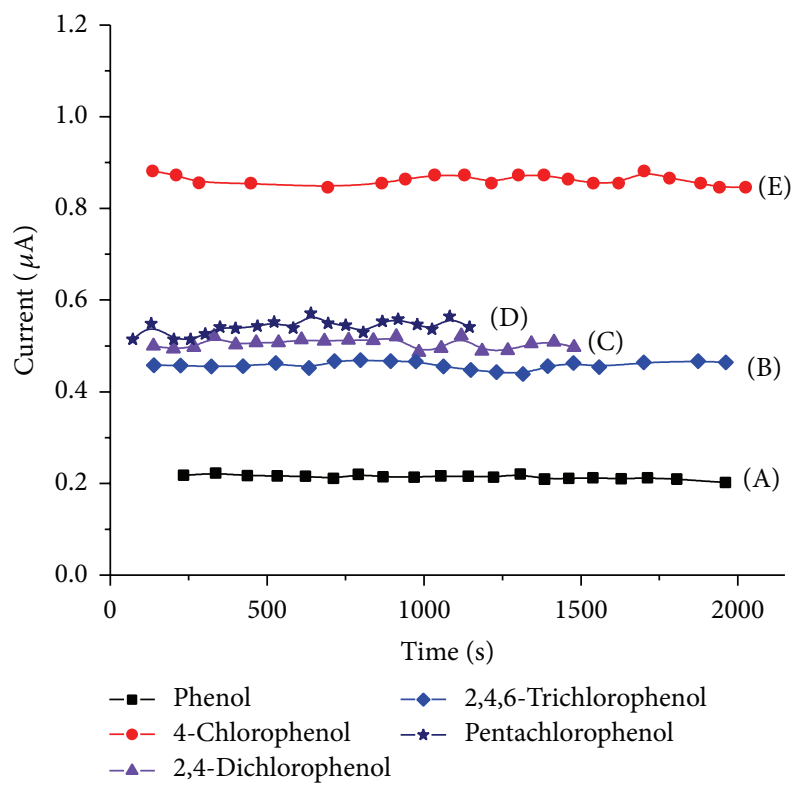

(b)

FIGURE 8: Amperometric flow injection responses of chlorophenol (a) and stability plot (b) obtained for 20 repetitive injections of phenol (A), 2,4,6-trichlorophenol (B), 2,4-dichlorophenol (C), pentachlorophenol (D), and 4-chlorophenol (E) at SWCNT/PEDOT/GCE as amperometric detector $\mathrm{pH} 7$ for phenol, 4-chlorophenol, and pentachlorophenol and 8 for 2,4-dichlorophenol and 9 for 2,4,6-trichlorophenol; other conditions are shown in Figure 7.

pentachlorophenol and $\mathrm{pH} 9$ for trichlorophenol were chosen for the subsequent experiments.

3.2.2. Sensor Performance. One of the most important performance parameters of a sensor is its operational stability. The operational stability of the SWCNT/PEDOT/GCE was investigated by measuring the current response of a series of 20 repetitive injections of $1 \times 10^{-5} \mathrm{M}$ phenol, $5 \times 10^{-5} \mathrm{M}$ 4-chlorophenol, $2 \times 10^{-5} \mathrm{M}$ 2,4-dichlorophenol, $2 \times 10^{-5} \mathrm{M}$ 2,4,6-trichlorophenol, and $5 \times 10^{-5} \mathrm{M}$ pentachlorophenol. The performance of SWCNT/PEDOT/GCE, as shown in Figure 8 , is highly remarkable since after 20 continuous 


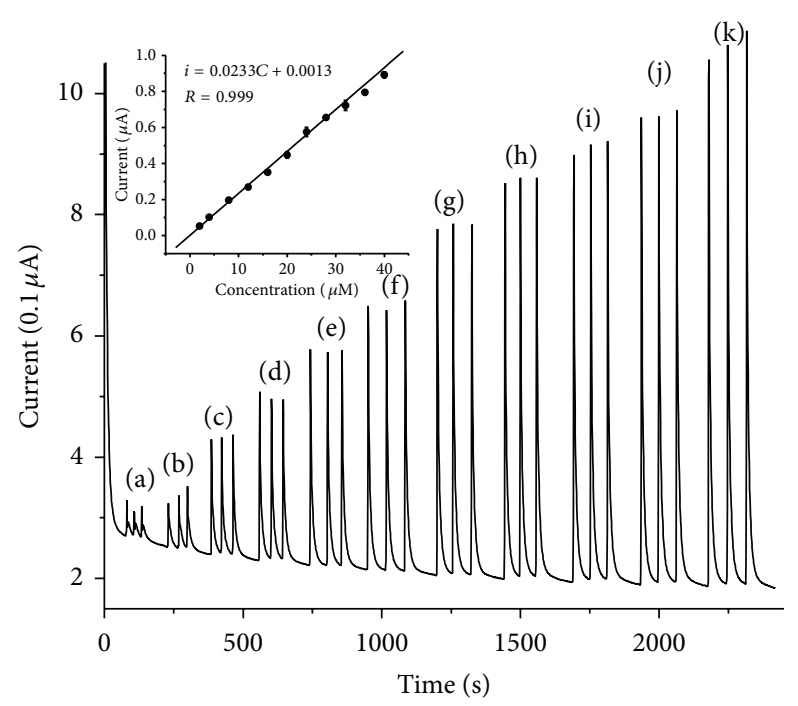

Figure 9: Current versus time responses to the sequential injections of $2,4,8,12,16,20,24,28,32,36$, and $40 \mu \mathrm{M}$ concentrations of 2,4,6-trichlorophenol (a)-(k); applied potential $0.700 \mathrm{~V}$; flow rate $1100 \mu \mathrm{L} \mathrm{min}^{-1}$; carrier solution: $0.1 \mathrm{M}$ acetate buffer $\mathrm{pH}$ 9. Inset: current $(\mu \mathrm{A})$ versus concentration $(\mu \mathrm{M})$.

TABLE 1: Reproducibility of the stability measurements obtained at SWCNT/PEDOT/GCE in flow injection system.

\begin{tabular}{lc}
\hline Phenolic compounds & RSD for $i_{p}(\%)$ \\
\hline Phenol & 0.47 \\
4-Chlorophenol & 1.82 \\
2,4-Dichlorophenol & 1.03 \\
2,4,6-Trichlorophenol & 1.07 \\
Pentachlorophenol & 1.60 \\
\hline
\end{tabular}

injections of the different phenolic analytes, the amperometric current response remains almost the same with standard deviation ranging from 0.47 to $1.82 \%$, as shown in Table 1. This demonstrates the good stability of the SWCNT/PEDOT/GCE as a detector in flow injection system.

\subsubsection{Analytical Performance of the SWCNT/GCE Detector} in the Flow Injection System. Figure 9 demonstrates the amperometric current responses of 2,4,6-trichlorophenol with increasing concentrations. As shown in the figure, the electrochemical responses were sharp and consistent with rapid and efficient electron transfer processes. The amperometric peak current increased linearly with increase in the concentration of 2,4,6-trichlorophenol. The observed relationships were employed to construct reliable analytical calibration curves as shown by the inset of Figure 9, with regression equation of $i_{\mu \mathrm{A}}=b x c_{\mu \mathrm{M}}+a$, where $b$ is the slope and $a$ is the intercept. The data obtained from the linear calibration curves under the optimum experimental conditions for each analyte are presented in Table 2 . The evaluated analytical characteristics of the calibration plots show wide linear range of detections with low limits of detection (LOD). The detection limits were calculated based on the $3 S_{b} / m$ criterion, where $m$ is the slope of the calibration graph for each analyte and $S_{b}$ was estimated as the standard deviation of the responses $(n=10)$ obtained from the repetitive analyte injections at the lowest concentration.

The analytical performance of the SWCNT/PEDOT/GCE evaluated for the amperometric responses has been compared with other enzyme/enzymeless electrochemical sensors reported recently as shown in Table 3. Characteristics such as type of electrode, linear range, sensitivity, and limit of detection achieved were compared. In addition to the simplicity of the preparation of the sensor wider or similar dynamic ranges, low detection limits and comparable sensitivity were obtained compared to the recently reported sensors/biosensors, as shown in Table 3. Hence, it can be clearly deduced that the SWCNT/PEDOT/GCE detector offers advantageous compared with other reported sensors/biosensors.

3.2.4. Interference Study. In order to evaluate the selectivity of the developed sensor, possible interferences in the detection of phenol at SWCNT/PEDOT/GCE were investigated by the addition of various ions and compounds to the carrier solution $(0.1 \mathrm{M}$ acetate buffer solution, $\mathrm{pH} 7)$ containing $5 \times 10^{-6} \mathrm{M}$ phenol. Hundred fold additions of common ions such as $\mathrm{Na}^{+}, \mathrm{K}^{+}, \mathrm{Ca}^{2+}, \mathrm{Mg}^{2+} \mathrm{Cu}^{2+}, \mathrm{Cl}^{-}, \mathrm{NO}_{3}^{-}$, and $\mathrm{SO}_{4}{ }^{2-}$ have no effect on the amperometric response of the designed electrode. The addition of two fold 2-nitrophenol, 4-nitrophenol, and pentachlorophenol did not interfere with the determination of phenol. As the optimum conditions of these compounds are similar due to their similarity in the oxidation of phenolic $\mathrm{OH}$ group, the effect from 4chlorophenol, 2,4-dichlorophenol, and 2,4,6-trichlorophenol is significant. The result suggests that this proposed method has good selectivity towards the determination of phenol and chlorophenols. However the analysis of phenols and chlorophenols needs separation prior to analysis.

3.2.5. Analytical Applications. In order to evaluate the validity of the proposed method phenol was taken. The SWCNT/PEDOR/GCE was applied for tape water samples which were prepared by adding $3 \mu \mathrm{M}$ of phenol. The results are given in Table 4 . When increased concentrations of phenol were injected to water sample quantitative recoveries of $99.14-102.87 \%$ were obtained. These results confirm that the designed detector can successfully be used for the quantitative determination of phenol and chlorophenols in flow injection system.

\section{Conclusion}

An electrochemical detector based on SWCNT/PEDOT modified GCE for the analysis of phenol and chlorophenols was developed. The constructed modified electrode was optimized for the amperometric determination of phenolic compounds in flow injection mode. The results demonstrate that the amperometric sensor exhibits a good analytical performance for the detection of phenolic compounds in flowing systems. The developed sensor is simple and efficient 
TABLE 2: Characteristics of the calibration graphs for the different phenolic compounds.

\begin{tabular}{lcccr}
\hline \multirow{2}{*}{ Compound } & \multicolumn{2}{c}{$i_{\mu \mathrm{A}}=b x c_{\mu \mathrm{M}}+a$} & Linear range $(\mu \mathrm{M})$ & \multirow{2}{*}{ Detection limit $(\mu \mathrm{M})$} \\
& Slope $(a)$ & Intercept $(b)$ & $0.1-260$ & 0.094 \\
Phenol & $0.018 \pm 0.00032$ & $0.013 \pm 0.0031$ & $0.4-180$ & 0.38 \\
4-Chlorophenol & $0.018 \pm 0.00024$ & $0.035 \pm 0.012$ & $0.4-120$ & 0.998 \\
2,4-Dichlorophenol & $0.025 \pm 0.00031$ & $0.056 \pm 0.056$ & $1.0-90$ & 0.999 \\
2,4,6-Trichlorophenol & $0.021 \pm 0.00026$ & $0.035 \pm 0.013$ & $2.0-110$ & 0.998 \\
Pentachlorophenol & $0.01 \pm 0.00017$ & $00.046 \pm 0.011$ & 0.998 \\
\hline
\end{tabular}

TABLE 3: Comparison of analytical performance of the calibration curves of SWCNT/GCE with different modified electrodes.

\begin{tabular}{|c|c|c|c|c|c|}
\hline Phenolic substrate & Detector/sensor & $\begin{array}{c}\text { Linear range } \\
(\mu \mathrm{M})\end{array}$ & Sensitivity & $\begin{array}{c}\text { Detection } \\
\text { limit }(\mu \mathrm{M})\end{array}$ & Reference \\
\hline \multirow{7}{*}{ Phenol } & Tyr/MWNTs/GCE & $4 \times 10^{-7}-1 \times 10^{-5}$ & $0.226 \mu \mathrm{A} / \mu \mathrm{M}$ & 0.2 & {$[39]$} \\
\hline & Polyacrylamide microgels/GCE & $5-22$ & $0.0042 \mu \mathrm{A} / \mu \mathrm{M}$ & 1.4 & {$[40]$} \\
\hline & $\mathrm{Au} / \mathrm{Cys} / \mathrm{Fe}_{3} \mathrm{O}_{4}-\mathrm{SiPGMA} / \mathrm{HRP}$ & $500-8500$ & $2.44 \mu \mathrm{A} / \mathrm{mM}$ & 28 & {$[22]$} \\
\hline & $\mathrm{GCE} /(\mathrm{CNT} / \mathrm{PEI}$ & $2.5-20$ & $27 \mathrm{nA} / \mu \mathrm{M}$ & 0.21 & {$[33]$} \\
\hline & $\begin{array}{l}\text { Multiwalled carbon nanotube } \\
\text { poly(pyrrole)-horseradish peroxidase } \\
\text { nanobiocomposite }\end{array}$ & $16-44$ & $1 \mathrm{nA} / \mu \mathrm{M}$ & 3.52 & {$[41]$} \\
\hline & MWNT-Nafion-Tyr/GCE & $1-19$ & $303 \mu \mathrm{A} / \mathrm{mM}$ & 0.13 & {$[16]$} \\
\hline & SWCNT/PEDOT/GCE & $0.1-260$ & $0.018 \mu \mathrm{A} / \mu \mathrm{M}$ & 0.094 & This work \\
\hline \multirow{6}{*}{ 4-Chlorophenol } & $\begin{array}{l}\text { self-assembled monolayer based } \\
\text { tyrosinase biosensors on } \mathrm{Au}\end{array}$ & $0.4-40$ & na & 0.15 & {$[18]$} \\
\hline & Polyacrylamide microgels/GCE & $2-24$ & $0.067 \mu \mathrm{A} / \mu \mathrm{M}$ & 0.03 & {$[39]$} \\
\hline & $\begin{array}{l}\text { laccase- and tyrosinase-based } \\
\text { biosensors }\end{array}$ & $1-10$ & $0.131 \mathrm{nA} / \mu \mathrm{M}$ & 0.09 & {$[42]$} \\
\hline & $\begin{array}{l}\text { Multiwalled carbon } \\
\text { nanotube-poly(pyrrole)-horseradish } \\
\text { peroxidase nanobiocomposite }\end{array}$ & $1.6-14.4$ & $8 \mathrm{nA} / \mu \mathrm{M}$ & 0.3 & {$[41]$} \\
\hline & $\begin{array}{l}\text { Biofunctional } \mathrm{ZnO} \text { nanoroad microarrays } \\
\text { on the nanocrystalline diamond electrode }\end{array}$ & $1-150$ & $339.3 \mu \mathrm{A} / \mathrm{mMcm}^{2}$ & 0.2 & {$[42]$} \\
\hline & SWCNT/PEDOT/GCE & $0.4-180$ & $0.018 \mu \mathrm{A} / \mu \mathrm{M}$ & 0.380 & This work \\
\hline \multirow{4}{*}{ 2,4-Dichlorophenol } & HRP/MWCNT/GCE & $1-100$ & $0.05 \mu \mathrm{A} / \mu \mathrm{M}$ & 0.38 & {$[43]$} \\
\hline & MWCNT/PEI/GCE & $0.1-100$ & $0.307 \mu \mathrm{A} / \mu \mathrm{M}$ & 0.075 & {$[44]$} \\
\hline & MIP/Chitosan/Nafion/GCE & $5-100$ & $0.067 \mu \mathrm{A} / \mu \mathrm{M}$ & 1.6 & {$[45]$} \\
\hline & SWCNT/PEDOT/GCE & $0.4-120$ & $0.025 \mu \mathrm{A} / \mu \mathrm{M}$ & 0.228 & This work \\
\hline \multirow{2}{*}{ 2,4,6-Trichlorophenol } & Enzymless GCE using preoxidation & $0.4-750$ & na & 0.04 & {$[46]$} \\
\hline & SWCNT/PEDOT/GCE & $1.0-90$ & 0.021 & $0.30 \mu \mathrm{A} / \mu \mathrm{M}$ & This work \\
\hline \multirow{2}{*}{ Pentachlorophenol } & MWCNT/epoxy composite & $2-12$ & $11 \mu \mathrm{A} / \mu \mathrm{M}$ & $0.8 \mu \mathrm{A} / \mu \mathrm{M}$ & {$[47]$} \\
\hline & SWCNT/PEDOT/GCE & $2.0-110$ & $0.01 \mu \mathrm{A} / \mu \mathrm{M}$ & $0.33 \mu \mathrm{A} / \mu \mathrm{M}$ & This work \\
\hline
\end{tabular}

na: not available.

TABLE 4: Recovery study.

\begin{tabular}{lccc}
\hline Sample $(\mu \mathrm{M})$ & Added $(\mu \mathrm{M})$ & Found $(\mu \mathrm{M})$ & Recoveries $(\%)$ \\
\hline 3 & 4 & 6.94 & 99.14 \\
3 & 8 & 10.96 & 99.64 \\
3 & 12 & 15.43 & 102.87 \\
\hline
\end{tabular}

and possesses a good operational stability and reproducibility. In general it is advantageous compared with other enzymztic and nonenzymatic sensors used in flow injection systems. The analytical performance makes possible the estimation of phenolic compound in tap water. The detector has good selectivity towards the determination of phenols and chlorophenols in terms of other interfering substances. However the analysis of mixtures of phenols and chlorophenols requires separation prior to analysis.

\section{Conflict of Interests}

The authors declare that there is no conflict of interests regarding the publication of this paper. 


\section{Acknowledgments}

One of the authors, Negussie Negash, is grateful to the Graduate School of Addis Ababa University for financial support and to the National University of Lesotho for giving him the chance to use the resources and facilities of their research laboratory.

\section{References}

[1] M. Naczk and F. Shahidi, "Phenolics in cereals, fruits and vegetables: occurrence, extraction and analysis," Journal of Pharmaceutical and Biomedical Analysis, vol. 41, no. 5, pp. 15231542, 2006.

[2] A. Peñalver, E. Pocurull, F. Borrull, and R. M. Marcé, “Solidphase microextraction coupled to high-performance liquid chromatography to determine phenolic compounds in water samples," Journal of Chromatography A, vol. 953, no. 1-2, pp. 7987, 2002.

[3] G. W. Muna, V. Quaiserova-Mocko, and G. M. Swain, "The analysis of chlorinated phenol solutions by capillary electrophoresis coupled with direct and indirect amperometric detection using a boron-doped diamond microelectrode," Electroanalysis, vol. 17, no. 13, pp. 1160-1170, 2005.

[4] "Phenols by Gas Chromatography, Capillary Column Technique: Environment Protection Agency Method 804," Washington, DC, USA, 1995.

[5] C. Proestos, D. Sereli, and M. Komaitis, "Determination of phenolic compounds in aromatic plants by RP-HPLC and GCMS," Food Chemistry, vol. 95, no. 1, pp. 44-52, 2006.

[6] A. S. Arribas, M. Martínez-Fernández, and M. Chicharro, "The role of electroanalytical techniques in analysis of polyphenols in wine," Trends in Analytical Chemistry, vol. 34, pp. 78-95, 2012.

[7] J.-S. Park, M. T. Brown, and T. Han, "Phenol toxicity to the aquatic macrophyte Lemna paucicostata," Aquatic Toxicology, vol. 106-107, pp. 182-188, 2012.

[8] M. Križman, D. Baričevič, and M. Prošek, "Determination of phenolic compounds in fennel by HPLC and HPLC-MS using a monolithic reversed-phase column," Journal of Pharmaceutical and Biomedical Analysis, vol. 43, no. 2, pp. 481-485, 2007.

[9] E. Hurtado-Fernández, M. Gómez-Romero, A. CarrascoPancorbo, and A. Fernández-Gutiérrez, "Application and potential of capillary electroseparation methods to determine antioxidant phenolic compounds from plant food material," Journal of Pharmaceutical and Biomedical Analysis, vol. 53, no. 5, pp. 1130-1160, 2010.

[10] Y. Tsuruta, S. Watanabe, and H. Inoue, "Fluorometric determination of phenol and $p$-cresol in urine by precolumn highperformance liquid chromatography using 4-(N-phthalimidinyl)benzenesulfonyl chloride," Analytical Biochemistry, vol. 243, no. 1, pp. 86-91, 1996.

[11] L. Pigani, M. Musiani, C. Pirvu, F. Terzi, C. Zanardi, and R. Seeber, "Electro-oxidation of chlorophenols on poly $(3,4-$ ethylenedioxythiophene)-poly(styrene sulphonate) composite electrode," Electrochimica Acta, vol. 52, no. 5, pp. 1910-1918, 2007.

[12] F. Maya, J. M. Estela, and V. Cerdà, "Flow analysis techniques as effective tools for the improved environmental analysis of organic compounds expressed as total indices," Talanta, vol. 81, no. 1-2, pp. 1-8, 2010.

[13] G.-Y. Kim, N. M. Cuong, S.-H. Cho, J. Shim, J.-J. Woo, and S.H. Moon, "Improvement of an enzyme electrode by poly(vinyl alcohol) coating for amperometric measurement of phenol," Talanta, vol. 71, no. 1, pp. 129-135, 2007.

[14] A. E. Böyükbayram, S. Kıralp, L. Toppare, and Y. Yağci, "Preparation of biosensors by immobilization of polyphenol oxidase in conducting copolymers and their use in determination of phenolic compounds in red wine," Bioelectrochemistry, vol. 69, no. 2, pp. 164-171, 2006.

[15] P. Wang, M. Liu, and J. Kan, "Amperometric phenol biosensor based on polyaniline," Sensors and Actuators B: Chemical, vol. 140, no. 2, pp. 577-584, 2009.

[16] Y.-C. Tsai and C.-C. Chiu, "Amperometric biosensors based on multiwalled carbon nanotube-Nafion-tyrosinase nanobiocomposites for the determination of phenolic compounds," Sensors and Actuators B: Chemical, vol. 125, no. 1, pp. 10-16, 2007.

[17] S. K. Ozoner, M. Yalvac, and E. Erhan, "Flow injection determination of catechol based on polypyrrole-carbon nanotubetyrosinase biocomposite detector," Current Applied Physics, vol. 10, no. 1, pp. 323-328, 2010.

[18] S. Campuzano, B. Serra, M. Pedrero, F. J. M. de Villena, and J. M. Pingarrón, "Amperometric flow-injection determination of phenolic compounds at self-assembled monolayer-based tyrosinase biosensors," Analytica Chimica Acta, vol. 494, no. 1-2, pp. 187-197, 2003.

[19] J. Li, L. S. Chia, N. K. Goh, and S. N. Tan, "Silica sol-gel immobilized amperometric biosensor for the determination of phenolic compounds," Analytica Chimica Acta, vol. 362, no. 2-3, pp. 203-211, 1998.

[20] R. Rawal, S. Chawl, and C. S. Pundir, "An amperometric biosensor based on laccase immobilized onto $\mathrm{Fe}_{3} \mathrm{O}_{4} \mathrm{NPs} / \mathrm{cMWCNT} /$ $\mathrm{PANI} / \mathrm{Au}$ electrode for determination of phenolic content in tea leaves extract," Enzyme and Microbial Technology, vol. 51, no. 4, pp. 179-185, 2012.

[21] Y. Li, C. Qin, C. Chen, Y. Fu, M. Ma, and Q. Xie, "Highly sensitive phenolic biosensor based on magnetic polydopaminelaccase- $\mathrm{Fe}_{3} \mathrm{O}_{4}$ bionanocomposite," Sensors and Actuators $B$ : Chemical, vol. 168, pp. 46-53, 2012.

[22] C. Emre, S. Mehmet, A. Baykal, and M. F. Abasıyanık, "A novel amperometric phenol biosensor based on immobilized HRP on poly(glycidylmethacrylate)-grafted iron oxide nanoparticles for the determination of phenol derivatives," Sensors and Actuators B: Chemical, vol. 173, pp. 396-405, 2012.

[23] T. Spătaru and N. Spătaru, "Voltammetric detection of phenol at platinum-polytyramine composite electrodes in acidic media," Journal of Hazardous Materials, vol. 180, no. 1-3, pp. 777-780, 2010.

[24] V. S. Vasantha and S.-M. Chen, "Electrocatalysis and simultaneous detection of dopamine and ascorbic acid using poly $(3,4-$ ethylenedioxy)thiophene film modified electrodes," Journal of Electroanalytical Chemistry, vol. 592, no. 1, pp. 77-87, 2006.

[25] S. Mehretie, S. Admassie, M. Tessema, and T. Solomon, "Voltammetric determination of paracetamol with poly (3,4ethylenedioxythiophene) modified glassy carbon electrode," Analytical and Bioanalytical Electrochemistry, vol. 3, no. 1, pp. 38-50, 2011.

[26] S. Mehretie, S. Admassie, T. Hunde, M. Tessema, and T. Solomon, "Simultaneous determination of $N$-acetyl- $p$ aminophenol and $p$-aminophenol with poly(3,4-ethylenedioxythiophene) modified glassy carbon electrode," Talanta, vol. 85, no. 3, pp. 1376-1382, 2011. 
[27] S. Mehretie, S. Admassie, M. Tessema, and T. Solomon, "Electrochemical study of niclosamide at poly(3,4-ethylenedioxythiophene) modified glassy carbon electrode," Sensors and Actuators B: Chemical, vol. 168, pp. 97-102, 2012.

[28] J. Wang, R. P. Deo, and M. Musameh, "Stable and sensitive electrochemical detection of phenolic compounds at carbon nanotube modified glassy carbon electrodes," Electroanalysis, vol. 15, no. 23-24, pp. 1830-1834, 2003.

[29] S. K. Vashist, D. Zheng, K. al-Rubeaan, J. H. T. Luong, and F.S. Sheu, "Advances in carbon nanotube based electrochemical sensors for bioanalytical applications," Biotechnology Advances, vol. 29, no. 2, pp. 169-188, 2011.

[30] J. M. Schnorr and T. M. Swager, "Emerging applications of carbon nanotubes," Chemistry of Materials, vol. 23, no. 3, pp. 646-657, 2011.

[31] T.-M. Wu, H.-L. Chang, and Y.-W. Lin, "Synthesis and characterization of conductive polypyrrole/multi-walled carbon nanotubes composites with improved solubility and conductivity," Composites Science and Technology, vol. 69, no. 5, pp. 639-644, 2009.

[32] P. Sundari and P. Manisankar, "Development of ultrasensitive surfactants doped poly(3,4-ethylenedioxythiophene)/multiwalled carbon nanotube sensor for the detection of pyrethroids and an organochlorine pesticide," Journal of Applied Electrochemistry, vol. 41, no. 1, pp. 29-37, 2011.

[33] A. S. Arribas, E. Bermejo, M. Chicharro et al., "Analytical applications of glassy carbon electrodes modified with multi-wall carbon nanotubes dispersed in polyethylenimine as detectors in flow systems," Analytica Chimica Acta, vol. 596, no. 2, pp. 183194, 2007.

[34] F. Qu, M. Yang, J. Jiang, G. Shen, and R. Yu, "Amperometric biosensor for chorine based on layer-by-layer assembled functionalized carbon nanotube and polyaniline multilayer film," Analytical Biochemistry, vol. 344, no. 1, pp. 108-114, 2005.

[35] J. S. Wang, P. Y. Chen, T. T. Huang, and M. S. Lin, "Enzymeless flow injection analysis of 2,4,6-trichlorophenol based on preoxidation cerium (IV) nitrate," International Journal of Electrochemical Science, vol. 7, pp. 9113-9121, 2012.

[36] M. A. Heras, S. Lupu, L. Pigani et al., "A poly(3,4-ethylenedioxythiophene)-poly(styrene sulphonate) composite electrode coating in the electrooxidation of phenol," Electrochimica Acta, vol. 50, no. 7-8, pp. 1685-1691, 2005.

[37] Z. Spitalsky, D. Tasis, K. Papagelis, and C. Galiotis, "Carbon nanotube-polymer composites: chemistry, processing, mechanical and electrical properties," Progress in Polymer Science, vol. 35, no. 3, pp. 357-401, 2010.

[38] R. S. Freire, N. Duran, and L. T. Kubota, "Development of a laccase-based flow injection electrochemical biosensor for the determination of phenolic compounds and its application for monitoring remediation of Kraft E1 paper mill effluent," Analytica Chimica Acta, vol. 463, no. 2, pp. 229-238, 2002.

[39] J. Ren, T.-F. Kang, R. Xue, C.-N. Ge, and S.-Y. Cheng, "Biosensor based on a glassy carbon electrode modified with tyrosinase immmobilized on multiwalled carbon nanotubes," Microchimica Acta, vol. 174, no. 3-4, pp. 303-309, 2011.

[40] J. P. H. Pérez, M. S.-P. López, E. López-Cabarcos, and B. López-Ruiz, "Amperometric tyrosinase biosensor based on polyacrylamide microgels," Biosensors and Bioelectronics, vol. 22, no. 3, pp. 429-439, 2006.
[41] S. Korkut, B. Keskinler, and E. Erhan, "An amperometric biosensor based on multiwalled carbon nanotube-poly(pyrrole)horseradish peroxidase nanobiocomposite film for determination of phenol derivatives," Talanta, vol. 76, no. 5, pp. 1147-1152, 2008.

[42] J. Zhao, D. Wu, and J. Zhi, "A novel tyrosinase biosensor based on biofunctional $\mathrm{ZnO}$ nanorod microarrays on the nanocrystalline diamond electrode for detection of phenolic compounds," Bioelectrochemistry, vol. 75, no. 1, pp. 44-49, 2009.

[43] S. Huang, Y. Qu, R. Li, J. Shen, and L. Zhu, "Biosensor based on horseradish peroxidase modified carbon nanotubes for determination of 2,4-dichlorophenol," Microchimica Acta, vol. 162, no. 1-2, pp. 261-268, 2008.

[44] A. S. Arribas, M. Moreno, E. Bermejo et al., "Application of carbon nanotube-modified electrodes as electrochemical sensors for the continuous monitoring of 2,4-dichlorophenol," Electroanalysis, vol. 23, no. 1, pp. 237-244, 2011.

[45] J. Zhang, J. Lei, H. Jua, and C. Wang, "Electrochemical sensor based on chlorohemin modified molecularly imprinted microgel for determination of 2,4-dichlorophenol," Analytica Chimica Acta, vol. 786, pp. 16-21, 2013.

[46] D. Vega, L. Agüí, A. González-Cortés, P. Yáñez-Sedeño, and J. M. Pingarrón, "Electrochemical detection of phenolic estrogenic compounds at carbon nanotube-modified electrodes," Talanta, vol. 71, no. 3, pp. 1031-1038, 2007.

[47] R. S. Freire, N. Durán, and L. T. Kubota, "Electrochemical biosensor-based devices for continuous phenols monitoring in environmental matrices," Journal of the Brazilian Chemical Society, vol. 13, no. 4, pp. 456-462, 2002. 


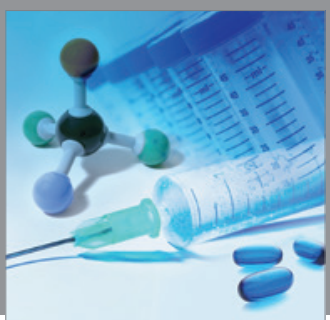

International Journal of

Medicinal Chemistry

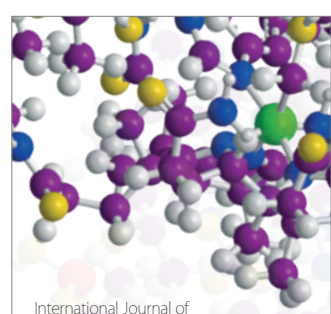

Carbohydrate Chemistry

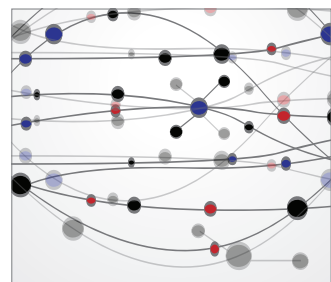

The Scientific World Journal
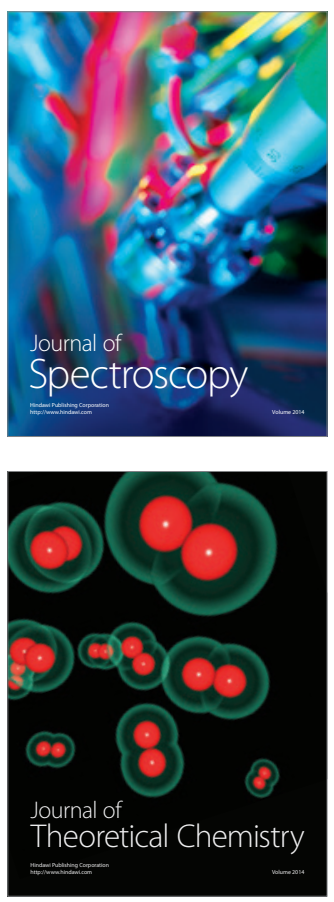
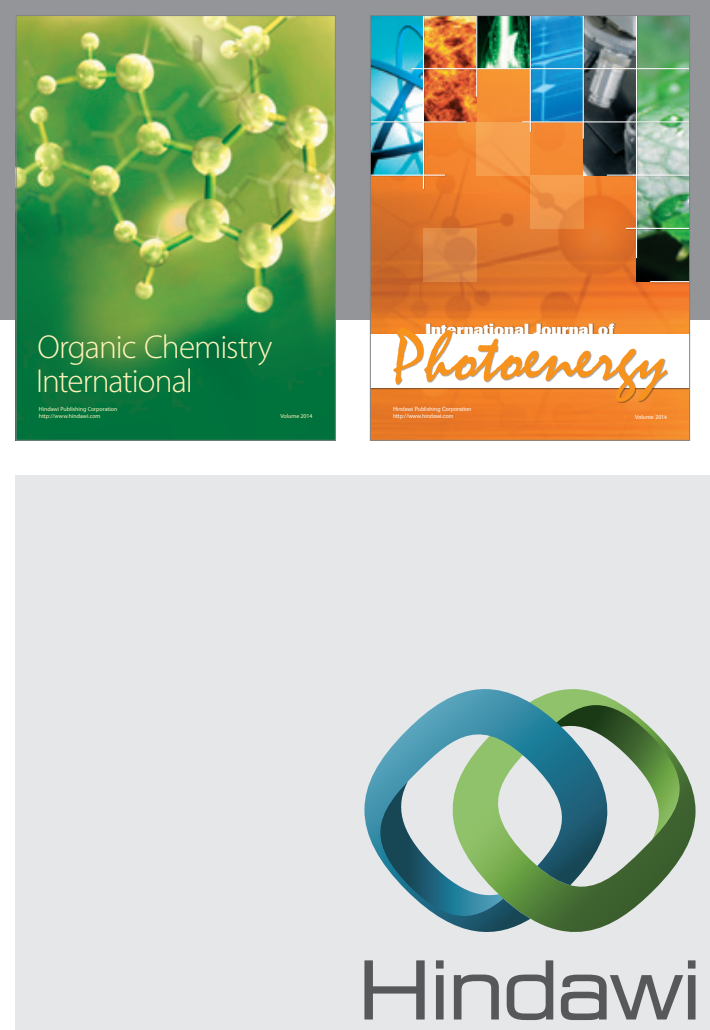

Submit your manuscripts at

http://www.hindawi.com
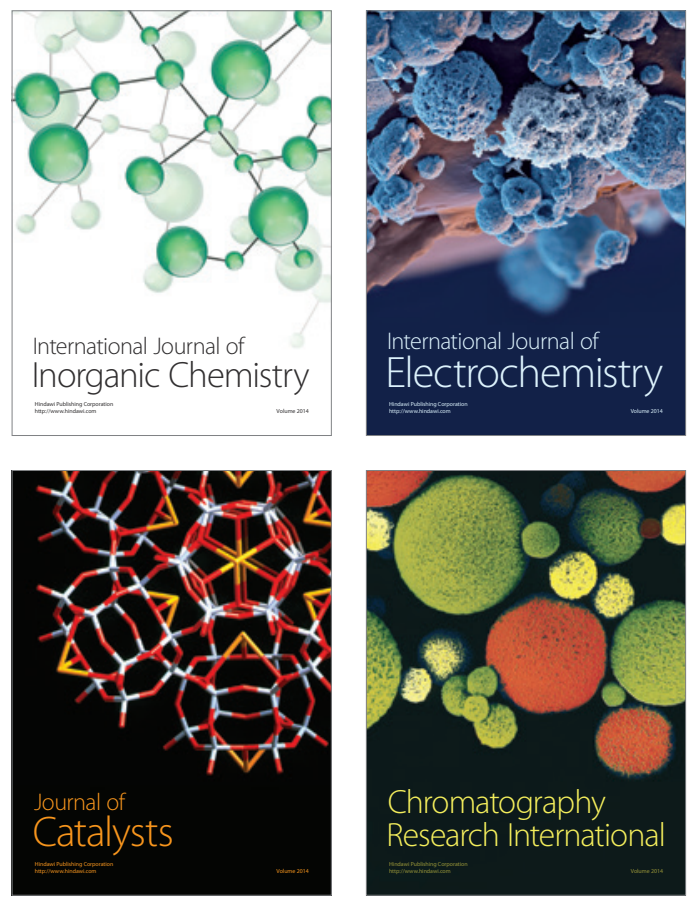
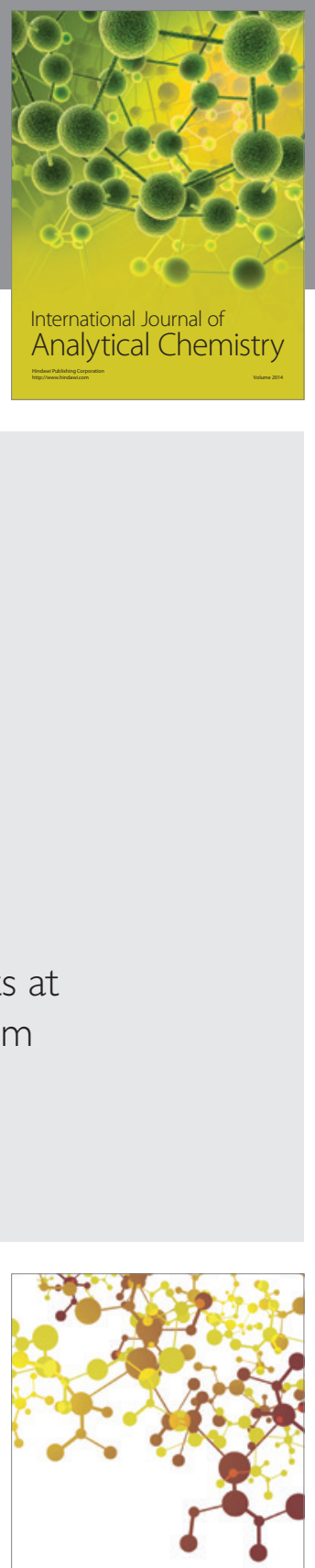

Journal of

Applied Chemistry
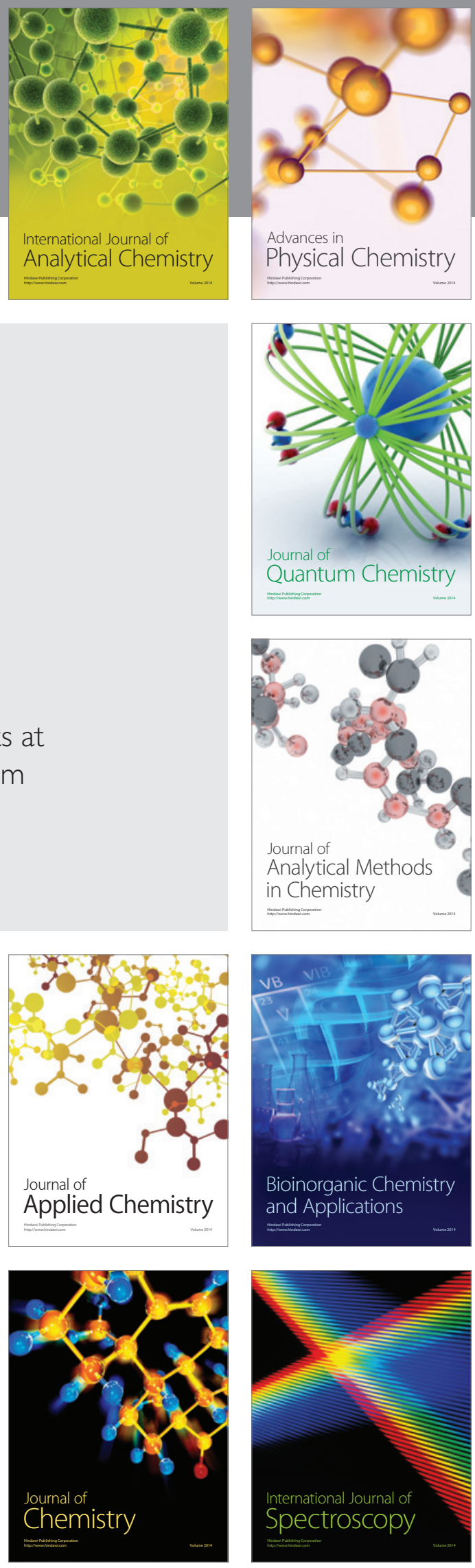